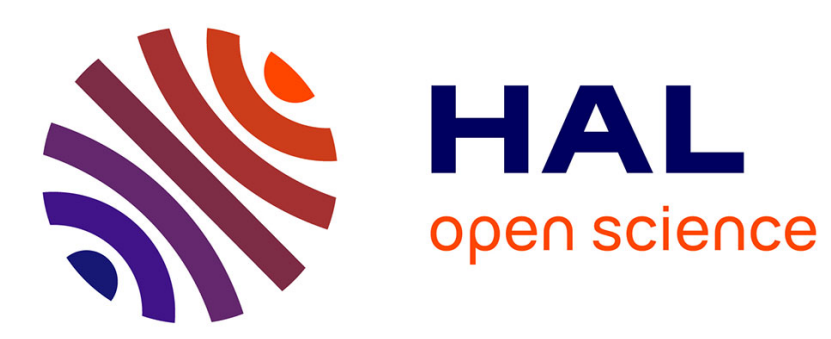

\title{
A broader view of the economic design of the X-bar chart in semiconductor industry
}

Bertrand Baud-Lavigne, Samuel Bassetto, Bernard Penz

\section{To cite this version:}

Bertrand Baud-Lavigne, Samuel Bassetto, Bernard Penz. A broader view of the economic design of the X-bar chart in semiconductor industry. International Journal of Production Research, 2009, 48 (19), pp.5839-5853. 10.1080/00207540903150593 . hal-00533424

\section{HAL Id: hal-00533424 https://hal.science/hal-00533424}

Submitted on 6 Nov 2010

HAL is a multi-disciplinary open access archive for the deposit and dissemination of scientific research documents, whether they are published or not. The documents may come from teaching and research institutions in France or abroad, or from public or private research centers.
L'archive ouverte pluridisciplinaire HAL, est destinée au dépôt et à la diffusion de documents scientifiques de niveau recherche, publiés ou non, émanant des établissements d'enseignement et de recherche français ou étrangers, des laboratoires publics ou privés. 


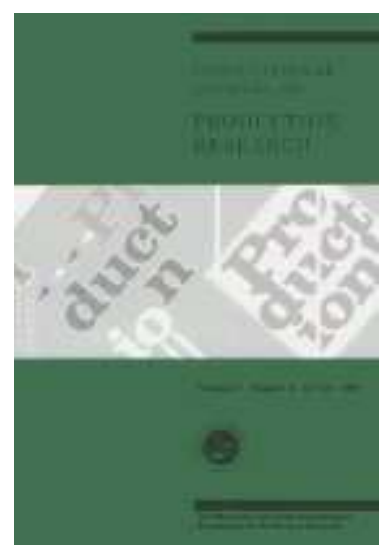

\section{A broader view of the economic design of the X-bar chart in semiconductor industry}

\begin{tabular}{|r|l|}
\hline Journal: & International Journal of Production Research \\
\hline Manuscript ID: & TPRS-2009-IJPR-0168 \\
\hline Manuscript Type: & Original Manuscript \\
\hline Author: & $13-$ Feb-2009 \\
\hline Complete List of Authors: & $\begin{array}{l}\text { baud-lavigne, Bertrand; Grenoble Institute of Technology, Dep. of } \\
\text { Ind. Eng. } \\
\text { Bassetto, Samuel; Grenoble Institute of Technology, Dep. of Ind. } \\
\text { Eng. } \\
\text { Penz, Bernard; Grenoble Institute of Technology, Dep. of Ind. Eng. }\end{array}$ \\
\hline Keywords: & $\begin{array}{l}\text { CONTROL CHARTS, DECISION SUPPORT SYSTEMS, } \\
\text { SEMICONDUCTOR INDUSTRY, QUALITY CONTROL, QUALITY } \\
\text { ENGINEERING }\end{array}$ \\
\hline Keywords (user): & CONTROL CHARTS, DECISION SUPPORT SYSTEMS \\
\hline
\end{tabular}

\section{scholarONE" \\ Manuscript Central}




\begin{abstract}
This paper starts from a notice made in semiconductor industry: process control system and especially control charts provide information that can be exploited for correlation analyses during process investigations. In this industry, key and costly investigations are made for improving yield and reducing scraps. Daily, engineering teams are working at manufacturing improvements. Without process data, their work could take much more time and lead to weak improvements. Nevertheless, design of process control systems and in particular control charts lacks from taking into account this remark. As their is no sound application to infer optimal control chart depending on «business parameters » like yield, scraps, customer audits... Meetings between several engineering teams (process control, quality, process integration, industrial engineering and production) occurs frequently to find an affordable quantity of controls for each operations. The literature point of view doesn't provide more recommandations to take into account the reuse of data into these costly investigations.

The paper investigates then this issue. For this first investigation, works have been focused on the design economics of control charts for a simplified process model. The paper translates into the Lorenzen and Vance model this concept. It simulates the design economic of control chart taking into account this new model and infers new optimal SPC set points. An analysis of this new link is made in a context of yield improvement, providing reference for knowing optimal quantity and frequency of controls.
\end{abstract}

Key words: economic design of control chart, scrap investigation, learning, ramp-up

\title{
1 Introduction
}

Semiconductor industry has to cope with severe environment, drifting processes, and sensitive products at any process disturbance. Information coming from tools and process measurements is a central element for learning how to master manufacturing systems. For each new semiconductor technology a learning process is followed, enabling the fine tuning of specifications, operating modes, control positions, etc. This process is followed to master operational risks before increasing the volume of production. Often, it is admitted by manufacturing teams that during early phases of this learning process, the number of controls have to be high in order to learn faster. However, milestone after milestone processes are expected to be more robust and stable. Progressively, it becomes possible to release controls as the process is better mastered. Maintaining high level of controls is then a nonsense [1] and the pressure to release controls increase drastically as the ramp-up process is going on.

Nevertheless, releasing controls remains an high risky action for managers. As studied by Gershwin and Kim [2], and Colledani [3], it increases the number of wafers produced between two control and by the way increases the risk of massive scrap. Often decision of affordable quantity of controls for each operations are taken during engineering meeting between several teams: process control, quality, process integration, production management... This can lead at sticking the level of control close to a predefined value reasonable in the organization, often far from an optimum. For example, it is a common practice in semiconductor industry to measure over 200 points of control, each wafers during first phases then to decrease near 50 points alsmost each lot and to reach less than 10 points per measured lots every 100 lots, when products are manufactured in volume. These control rates are not really linked at those provided by classical SPC design methods (either pure statistical design or economic design methods), which also fail to take into account business parameters like data reuse or global cost. There is then an opportunity to develop a decision aided tool to help balancing optimal parameters depending on scrap rate. The design of control charts takes care of external parameters, usually considered by managers like scrap rate and the reuse of quality information.

The aim of this paper is to provide a framework to help this decision process by taking into account both statistical and informational issues. This paper proposes a two stages approach toward such a tool :

- The first step enhances the now classical Lorenzen and Vance's model [4]. The cost of one scrap is far more important than out of control ones and data collected from quality measurements are used during scrap analyzes for building root causes, curative and preventative action plans. It adds the influence between number of points, control frequency 
and the necessary time to solve scrap issues.

- The second fold consists in discussing the evolution (through the simulation) of sampling points and rates under the condition of scrap rate evolution.

The paper is structured over fivesections. In a first part, the paper goes through a literature review of economic design of control chart. Then, the paper presents the model enhancing the Lorenzen and Vance's once. The paper presents how simulations have been performed and several results. These two parts represent the first stage, discussed above. Then the paper goes through the second stage, also aforementioned. The paper ends with perspectives.

\section{Literature review}

The questionning of interaction between quality and manufacturing operation has been adressed recently by Gershwin and Kim [2], and Colledani [3]. Their works are firsts investigations of how quality considerations can modify the production control.

The design of control charts involves the selection of three parameters: sampling size (n), control frequency (h), and control limits (L) in order to detect earlier tools and processes shifts [5]. Economic design of control chart is a method which aims at determining these parameters of a control chart in optimizing a cost function of the process monitored. Usually, it considers parameters inner to the monitored process, such as the cost of sampling and analyzing, quality cost and behavior of the machine.

Classical criteria as statistical properties can be considered as economic variables. Duncan, [6] proposes in 1956 the economical optimization of a $\bar{X}$ control chart of a process which is only shut down during repairing. Several works around this model during the next 40 years have been interesting on the others types of control charts, adaptation to specific situations and resolution methods. A breakthrough has been the generalization of all these models by Lorenzen and Vance [4]. It is nowadays a reference in economic design, as it can be easily implemented and adapted.

Optimizing the design of control charts in an economic manner affords many opportunities to take into account external parameters of the process. One example is the adaptation of the economic design to semiconductor industries by Jang et al. [7]. This study details cost parameters of the Lorenzen and Vance's model, specifically the quality cost by using opportunity cost of the non-conformities.

Several critics and enhancements have been performed over economic control chart design. Critics of this type of design highlight a lack of statistical properties, and the difficulties to evaluate correctly the input parameters [8]. Improvements of the Lorenzen and Vance model have been done in adding statistical constraints [9], and by proposing more robust implementation: in using multiple scenarios in the optimization [10] or in expressing the input parameters in ranges of values [11]. Extensions of the economic design have also been done through adaptive control [12]. We recommend the overview of Tagaras [13] for more details about adaptive control.

Another lack pointed by Deming and Edwards [14] and Woodall [8] in the economic design theory is the aim at maintaining the process in its initial situation, without any emphasis on continuous improvement. Silver and Rohleder [15] propose a dynamical optimization of the design parameters by reducing the out-of-control frequency at each cycle during the expected improvement period. This reflect the fact that improvement is inherent to the process and should be considered as it affect one design parameters. Weheba and Nickerson [16] consider the economic design of control chart as a reactive process and have a proactive approach, by adding the cost function of improvement in the process. Instead of considering improvement as a possibility to reduce costs, the targeted quality is imposed. The concept of "better quality level" is implemented in their model as lower process drifts.

In the current literature, fact that controls retrieve data, which is employed to solve manufacturing issues, seems not exploited. However, data coming from tools, process and product controls are re-employed during problem solving sessions. An example is provided by a case study on the semiconductor industries [17]. This literature review has not retrieved any article about links between the reuse of process control data and the design of control charts. This paper investigates this link. Moreover, considering yield improvement, the paper discusses how quality control equilibriums (number of points to be measured, sampling rates in particular) will be modified by the decrease of scrap rate due to learning. Learning, as scrap rate or yield will be considered as exogenous factors of control chart design in this paper.

\section{Description of the model and the cost function}

This paper proposes an enhancement of the Lorenzen and Vance's economic design of control charts model, by embedding a link between control plan definition (sampling rate and number of controls) and duration of scrap investigation. This enhancement comes from literature review and authors experience in semi-conductor industry. 
The manufacturing process is composed of $\mathrm{N}$ stages, as presented Figure 1, followed by a $\bar{X}$ control chart. It is similar to the model of Colledani [3], which investigates the equilibrium between process control actions and line balancing ones.

Usually, SPC measurements are employed for monitoring processes drifts. Each out of control is followed by a local action. Most of the time, this action is a predefined procedure known to be a fast answer at the drift. These kinds of actions remain low cost and simple to perform, so that any operator can apply it. They are full part of local continuous improvement. Long run investigations are usually not allowed within this frame.

At the end of the process, the product is qualified by functional tests. These controls are employed to sort dices and wafers and to scrap those rejected. When a product is considered faulty, long run investigations are performed to detect faulty process stages. Data from the entire production line are used to investigate, through data analysis algorithms (commonalities, clustering for example). These actions are performed by high qualified technicians and engineers. They are time consuming and rely on available process data. Speeding this stage remains a major stake as it is at the heart of process learning and global continuous improvement [18].

In the remainder, the paper aims to determine parameters of each SPC controls that will minimize the costs of the whole model.

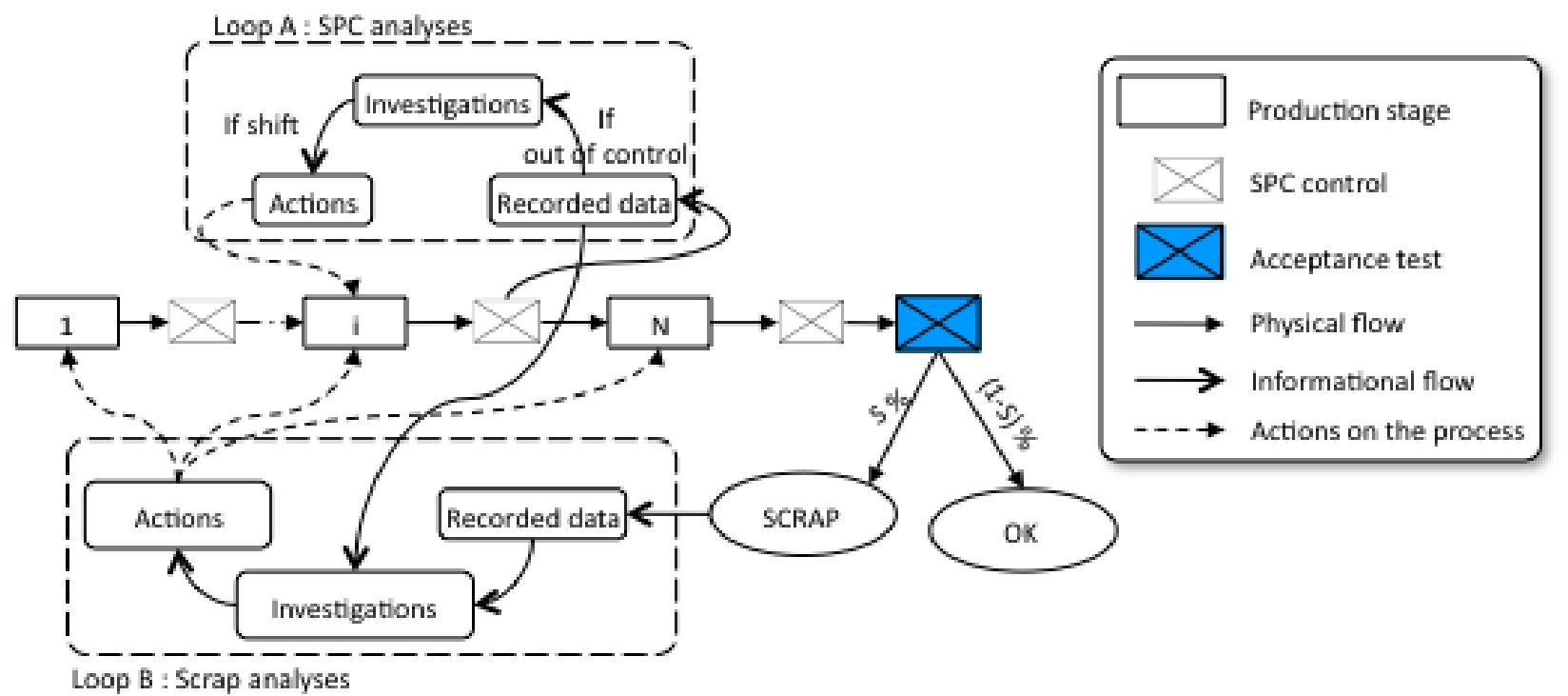

Figure 1: Modeling of the production line and the quality controls

In order to simplify the mechanism of the model, only the size (n) and the interval between two sampling (h) will be optimized, given control limit (L). In order to focus the analysis on the effect of the scrap investigation costs and to constrain the solution space, $\mathrm{L}$ is held at three in our optimization as presented by Weheba and Nickerson [16]. This assumption respects the "six sigma" method recommendations. When relaxing this assumption, constraints have to be added on the "average run length (ARL)" to ensure statistical properties of the optimization, as in the economicalstatistical design of Saniga [9]. Besides, emphasis should be put in optimization methods to maintain a short time optimization.

The function to minimize is:

$$
\min _{n_{i}, h_{i}}\left(\sum_{i=1}^{N} f_{i}\left(n_{i}, h_{i}\right)\right)+b\left(\frac{n_{1}}{h_{1}}, \frac{n_{2}}{h_{2}}, \ldots, \frac{n_{N}}{h_{N}}\right)
$$

Where $\mathbf{f}_{\mathbf{i}}$ is the cost function of the $\mathrm{i}^{\text {th }}$ SPC control and $\mathbf{b}$ is the cost function of the scrap investigation.

The cost of the investigation (function b) has been formulated in function of the quantity of SPC control done during the production. At stage i, if $n_{i}$ is the size of a sample and $\frac{1}{h_{i}}$ the frequency of sampling, then $\frac{n_{i}}{h_{i}}$ is the quantity of controls per hour. Each control is assimilated at one measurement retrieving data. As mentioned before, this amount of data is stored and used both for local and global improvement. The more information is available, the more analyses can 
be driven without any extra test. Time of investigation is shortened and extra costs are reduced with high quantity of control.

In this model, $\mathbf{b}$ is two folded. It is made of a fixed cost $\mathrm{C}$ when no information are available and a function $\mathbf{- g}()$ which decreases the cost when available SPC data increases. As the problem has been formulated as an optimization process, $\mathrm{C}$ can be suppressed. In the remainder, only $\mathbf{g}($ ) will be taken in account.

The function to minimize becomes then

$$
\min _{n_{i}, h_{i}} \sum_{i=1}^{N} f_{i}\left(n_{i}, h_{i}\right)+b\left(\frac{n_{1}}{h_{1}}, \frac{n_{2}}{h_{2}}, \ldots, \frac{n_{N}}{h_{N}}\right)=\min _{n_{i}, h_{i}} \sum_{i=1}^{N} f_{i}\left(n_{i}, h_{i}\right)+C-g\left(\frac{n_{1}}{h_{1}}, \frac{n_{2}}{h_{2}}, \ldots, \frac{n_{N}}{h_{N}}\right)=\min _{n_{i}, h_{i}}\left(\sum_{i=1}^{N} f_{i}\left(n_{i}, h_{i}\right)-g\left(\frac{n_{1}}{h_{1}}, \frac{n_{2}}{h_{2}}, \ldots, \frac{n_{N}}{h_{N}}\right)\right)
$$

\section{Model studied}

For the sake of simplification, a model composed only of the $\mathrm{i}^{\text {th }}$ stage and the scrap investigation has been implemented. It is presented Figure 2.

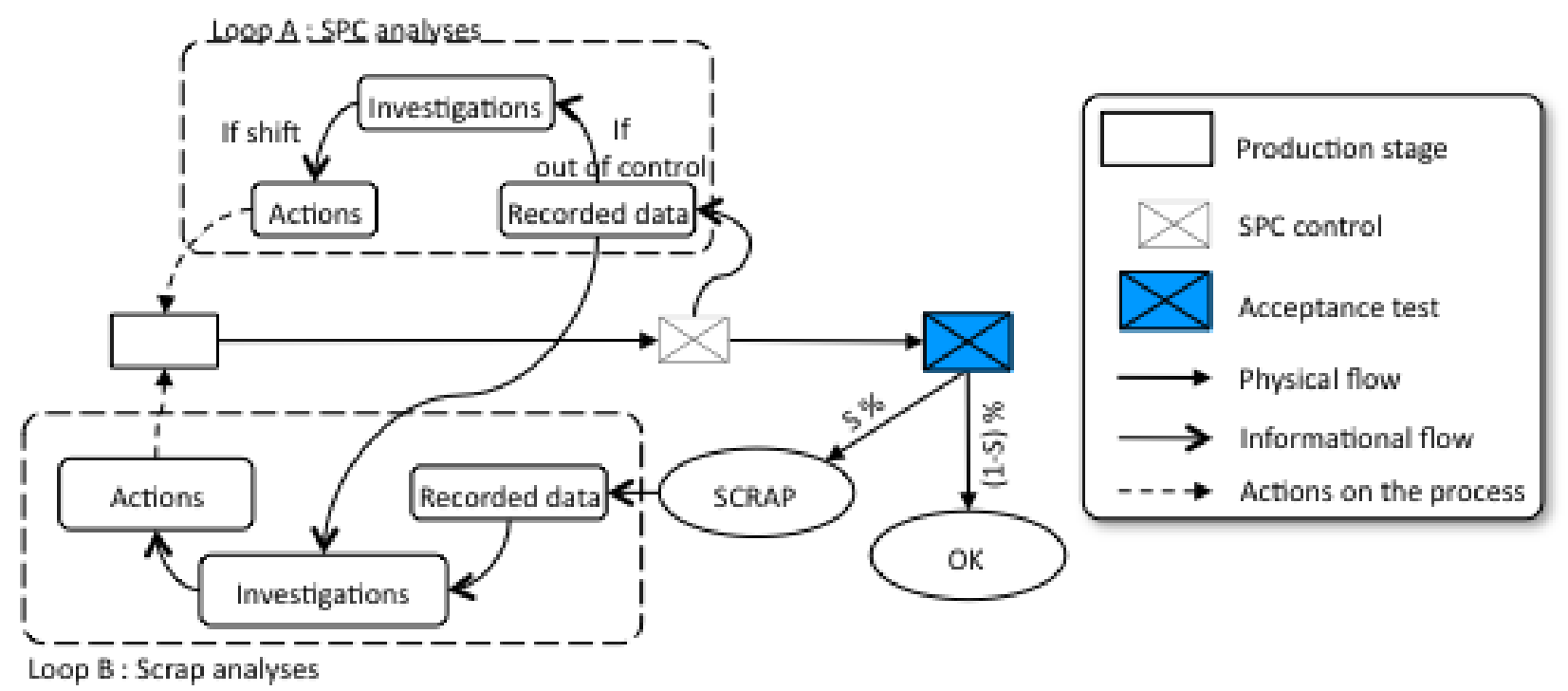

Figure 2: Simplified model

The function to minimize is simplified to:

$$
\min _{n, h}\left(f(n, h)-g\left(\frac{n}{h}\right)\right)
$$

Notations and the cost function of the economic design model are taken from Lorenzen and Vance model [4]. This function follow the classical control cycle detailed Figure 3, each parameter and cost are described Table 1.1. 


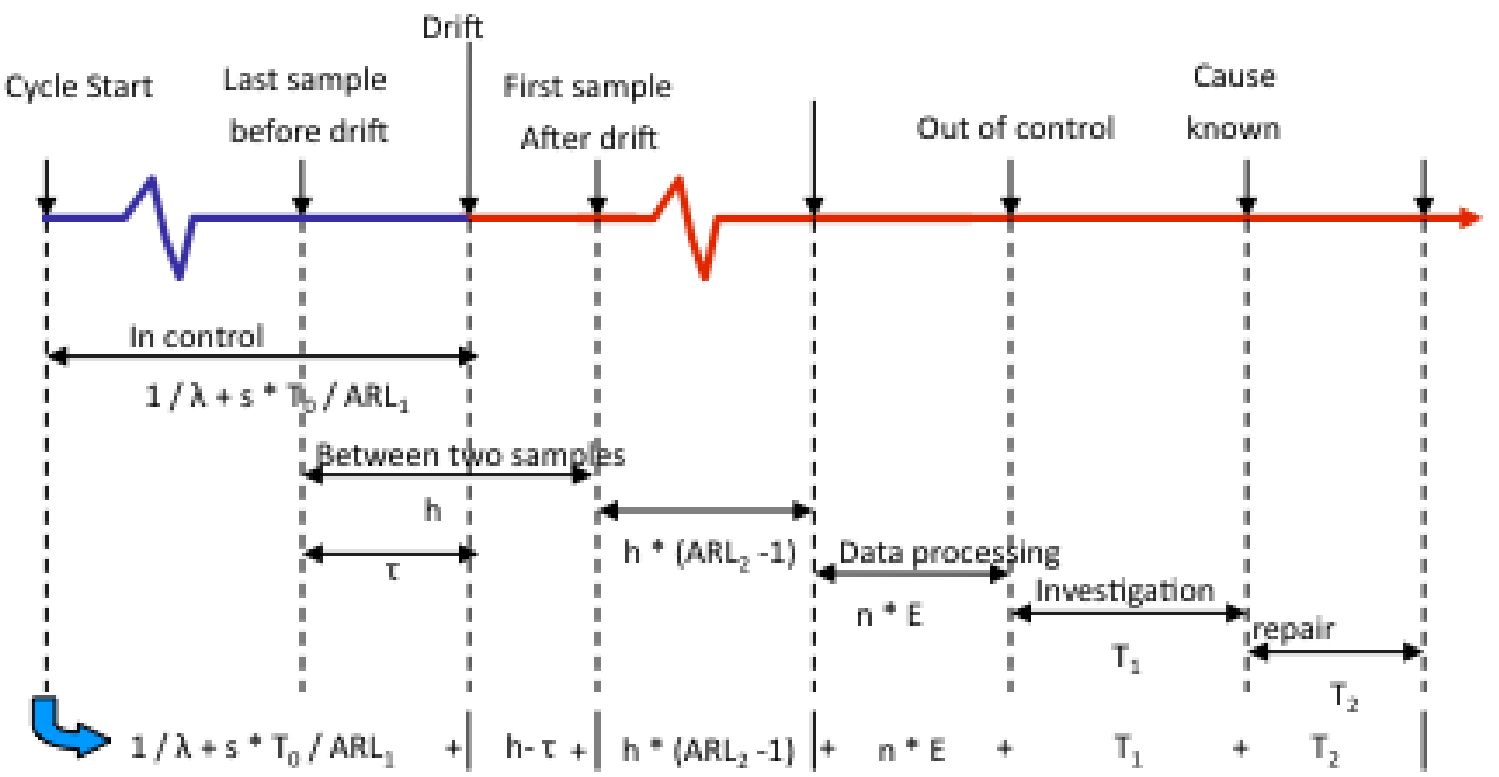

Figure 3: A control cycle

The cycle starts in control. Their is a control before the drift. The duration of the " in control» state is $1 / \lambda+s^{*}$ $\mathrm{T}_{0} / \mathrm{ARL}_{1} . \tau$ is the mean time between the last sample before the drift and the drift. $\mathrm{h}$ is the time between samplings. However the control chart cannot detect immediately the drift. Then $\mathrm{h}^{*}\left(\mathrm{ARL}_{2}-1\right)$ time passes until the sampling which will detect the out of control. Between the sample and the out of control signal, their is a data treatment duration : $\mathrm{n} * \mathrm{E}$. After the out of control, is $T_{1}$ the investigation time, and $T_{2}$, the repair time. At the end of $T_{2}$, the issue is fixed and the process is released in control.

\begin{tabular}{|c|c|c|}
\hline Type & Variable & Designation \\
\hline \multirow[t]{3}{*}{ Design Variables } & $\mathrm{n}$ & sample size \\
\hline & $\mathrm{h}$ & hours between samples \\
\hline & $\mathrm{L}$ & number of standard deviation from control limit to center line \\
\hline \multirow[t]{4}{*}{ Process Parameters } & $\lambda$ & $1 /$ mean time process is in control \\
\hline & $\Delta$ & number of standard deviation slip when out of control \\
\hline & $C_{0}$ & Quality cost / hour while In Control (IC) \\
\hline & $C_{1}$ & Quality cost / hour while Out Of Control (OoC) \\
\hline \multirow[t]{3}{*}{ Sample parameters } & $\mathrm{a}$ & fixed cost per sample \\
\hline & $\mathrm{b}$ & cost per unit sampled \\
\hline & $\mathrm{E}$ & time to sample and chart on item \\
\hline \multirow[t]{5}{*}{ OOC Parameters } & $\mathrm{Y}$ & cost per false alarm \\
\hline & $\mathrm{W}$ & cost to locate and repair the assignable cause \\
\hline & $T_{0}$ & expected search time when false alarm \\
\hline & $T_{1}$ & expected time to discover the assignable cause \\
\hline & $T_{2}$ & expected time to repair the process \\
\hline \multirow[t]{4}{*}{ Calculated variables } & $\mathrm{s}$ & mean number of sample while IC \\
\hline & $\tau$ & mean time between last sample while IC and the drift \\
\hline & $A R L_{1}$ & mean number of sample between an out of control while IC \\
\hline & $A R L_{2}$ & mean number of sample between an out of control sample while OoC \\
\hline
\end{tabular}




\section{Table 1.1 List of parameters}

The hourly cost function of a classical economic design is: $f(n, h)=\frac{C_{N C}+C_{O o C}+C_{S}}{T_{\text {cycle }}}$

Where: $\quad T_{\text {cycle }}$ is the length of a cycle from the production beginning to the occurrence of an assignable cause, then its detection, and finally its repair.

$$
T_{\text {cycle }}=\frac{1}{\lambda}+\frac{Y \cdot s}{A R L_{1}}-\tau+h \cdot A R L_{2}+n \cdot E+T_{1}+T_{2}
$$

$C_{N C}$ is the non-conformities costs for a cycle.

$$
C_{N C}=\frac{C_{0}}{\lambda}+C_{1}\left(-\tau+n \cdot E+h \cdot A R L_{2}\right)
$$

$C_{O o C}$ is the false alarm and detection costs for a cycle.

$$
C_{\text {OoC }}=\frac{Y . S}{A R L_{1}}+W
$$

$C_{S}$ is the direct sampling cost for a cycle.

$$
C_{S}=(\mathrm{a}+\mathrm{b} . n) \quad \frac{(1 / \lambda-\tau+\mathrm{n} \cdot \mathrm{E}+\mathrm{h} \cdot \mathrm{ARL} 2)}{h}
$$

For a detailed explanation of this classical model, authors recommend to read the paper of Lorenzen and Vance [4].

\section{Expression of the gain function}

$g()$ is the gain per hour on the scrap investigation. It is estimated by the following function:

$g\left(\frac{n}{h}\right)=I . C_{I n v}\left(\frac{n}{h}\right)$

Where :

- $I$ is the number of investigations per hour. $I$ equals the Scrap rate (or mechanical yield) times Number of products per hour.

- $C_{I n v}\left(\frac{n}{h}\right)$ is the expected gain per investigation. It equals the maximum gain times $j\left(\frac{n}{h}\right)$

$\circ j()$ expresses the impact of the quantity of available information, that is the quantity of control done, on the gain of investigation. $j\left(\frac{n}{h}\right) \in[0,1]$

- Several functions have been tested, such as linear, logarithmic or sigmoid ones. To translate the fact that the value of data is higher when we present a first order model: $j\left(\frac{n}{h}\right)=1-e^{-\mathrm{Q} \cdot \frac{n}{h}}$, where is Q a constant which determines both the slope of the function and the maximum of profitable information.

Even if data are reused for scrap and yield improvement, the learning mechanism remains unknown and will be considered as a black box in this paper. As a consequence, scrap rate will be considered as exogenous parameters of control charts design.

\section{Simulation and results}

The case study used to test this model generalizes a typical process in the semi conductor industry [19] in a 300mm wafer fab. The maximum gain is estimated at $2500 €$ per investigation, and is reached when controls are about 200 units per hour, that is Q is around 0.029 . We assume that the process drifts to 1 sigma every 24 hours in average. Costs are estimated upon a cost of a machine of $300 € / \mathrm{h}$. $C_{0}$ is roughly estimated at $160 € / \mathrm{h}$. $C_{1}$ reaches $640 € / \mathrm{h}$. 
Sampling parameters considers a fixed cost per sample of $2 €$ (a $1000 €$ test wafer is used about 500 times), a time to sample 17 units takes about 5 minutes i.e. $5.10^{-3} \mathrm{~min} /$ unit sampled. This leads to a variable cost of $1.4706 €$ (time to sample $x 300 € / h)$. The search time following an out of control is one hour, whenever the process is in control or not. So the cost of a false alarm is $300 €(1$ hour $x 300 € / h)$. The time to repair the process is 4 hours, and the cost to locate and repair the assignable causes is $2000 €(5$ hours $\times 300 € / \mathrm{h})$. Parameters are synthesized in appendix. ARL $\mathrm{A}_{1}$, the mean number of sample between an out of control while IC is estimated at and $\mathrm{ARL}_{2}$, the mean number of sample between an out of control sample while OoC is estimated at

The maximum gain over one scrap analysis is estimated at $2500 €$. The scrap rate (also named $\mathrm{S}$ ) for this simulation is $50 \%$. The manufacture processes 12 products per hour.

A synthesis of these parameters is presented Table 1.2

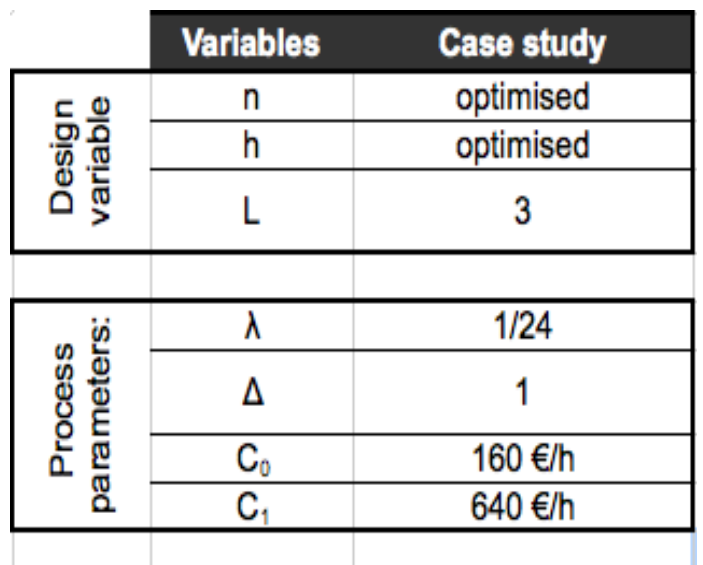

\begin{tabular}{|c|c|c|}
\hline \multirow{3}{*}{ 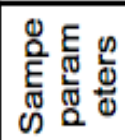 } & $a$ & $2 €$ \\
\hline & $b$ & $1.4706 €$ \\
\hline & $E$ & .004902 \\
\hline
\end{tabular}

\begin{tabular}{|c|c|c|}
\hline \multirow{5}{*}{ 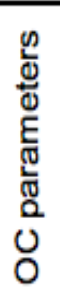 } & $Y$ & $300 €$ \\
\hline & W & $2000 €$ \\
\hline & $T_{0}$ & $1 \mathrm{~h}$ \\
\hline & $T_{1}$ & $1 \mathrm{~h}$ \\
\hline & $\mathrm{T}_{2}$ & $4 h$ \\
\hline
\end{tabular}

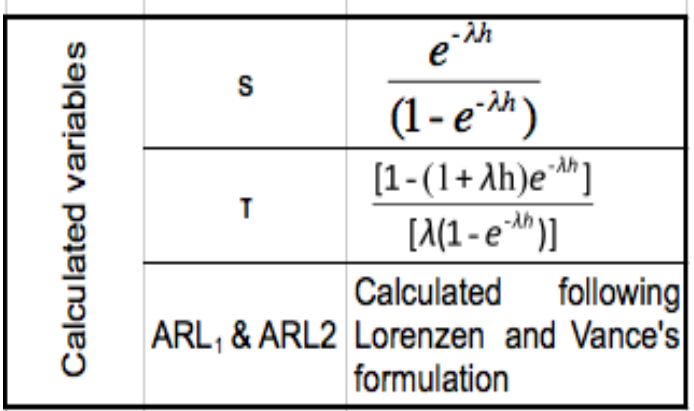

Table 1.2: Model's paramters

The optimization is a systematic enumeration of the possible combinations of $\mathrm{n}$ and $\mathrm{h}$, in a few steps: first, a rough step for $\mathrm{n}$ and $\mathrm{h}$ is used to determine the valuable scale (ie $\mathrm{n}$ is search between 1 and 1000 with a step of 10 , h between 0 and 20 with a 0.1 step). Then the window is narrowed and the step is refined. Thanks to modern computers and the fact that we consider L given, the enumeration is fast and take less than five seconds for 40000 combinations tested on a Pentium M processor at $2.1 \mathrm{GHz}$ with 1 Go RAM. The program has been made in $\mathrm{C}++$ with graphic representation using Root ${ }^{1}$ (CERN) libraries, and is available upon request from the authors.

\footnotetext{
1 http://root.cern.ch/
} 
The results are represented in Figure 4 and Figure 5:

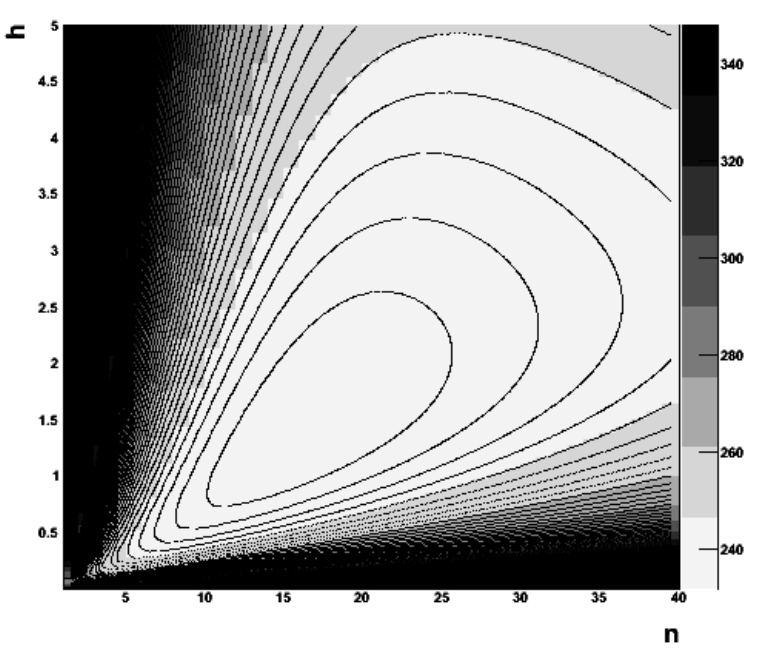

Figure 4: Cost per hour of the classical economic design

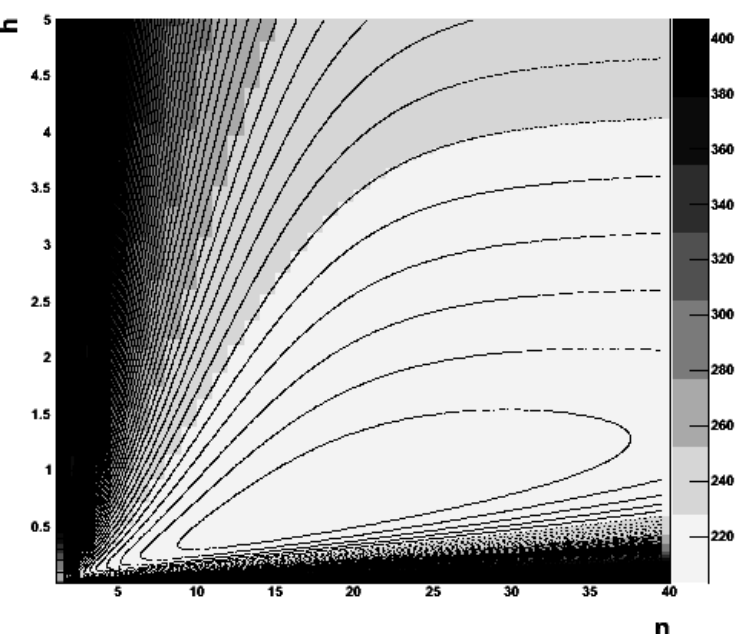

Figure 5: Cost per hour with integration of the scrap investigation costs

Curves represent « iso » values of $f(n, h)-g\left(\frac{n}{h}\right)$ depending on $\mathrm{n}$ and $\mathrm{h}$. Costs are elevated when

- $\mathrm{n}$ is low, because of false alarm and scrap investigation costs

- $\mathrm{h}$ is low and $\mathrm{n}$ is high, because of out-of-control and direct sampling costs

The integration of the scrap investigation costs in the economic design of control chart modifies quantity of control optimum. Indeed, in our example, quantity of controls increases from $10.85 \mathrm{u} /$ hour to $25.17 \mathrm{u} /$ hour, the interval between two samples decreases from 1.475 hour to 0.715 hour and the sample size increases from 16 to 17 points. This result shows that: the reuse of SPC data for speeding scrap investigations has a clear impact on SPC parameter and tends to increase the number of controls. This connection proves that other sampling plan choices would lead at higher process control cost.

\section{Discussions about the use of this model in a ramp-up context}

During the ramp up phase of a new product, significant improvement in the process happens. Preventive actions improve yields, manufacturing stability and robustness. Therefore, production costs and scrap rate are decreasing rapidly [20]. In the semiconductor context, priority is to reduce ramp-up time and to achieve as soon as possible a good yield [21], because of the product life cycle, characterized by decreasing of the prices and short life time [7]. Experience on the past product and learning curves [20] can provide estimation of the scrap rate.

The model assumes that $\mathrm{S}$ is an exogenous parameter toward $C_{0}$ and $C_{1}$. When the process is in control, the monitored tool produces nevertheless some scraps. Wafers can be scratched or broken, or contribute to the final yield reduction, without knowing clearly each process stage implication. As final scrap rate evolves during the manufacturing ramp-up or the technology lifecycle, there is a relation between $C_{0}$ and $\mathrm{S}$. Nevertheless, as it is possible to know broken and scratches costs at each process stage, estimating the true contribution of each operation upon hundreds of them to the final yield is hard to perform. That is why learning is considered only through the evolution of $\mathrm{S}$, while $C_{0}$ and $C_{1}$ are assumed to be fixed quality costs.

Following curves present the evolution of optimal $\mathrm{n}$ and $\mathrm{h}$ parameters depending on scrap rate. 


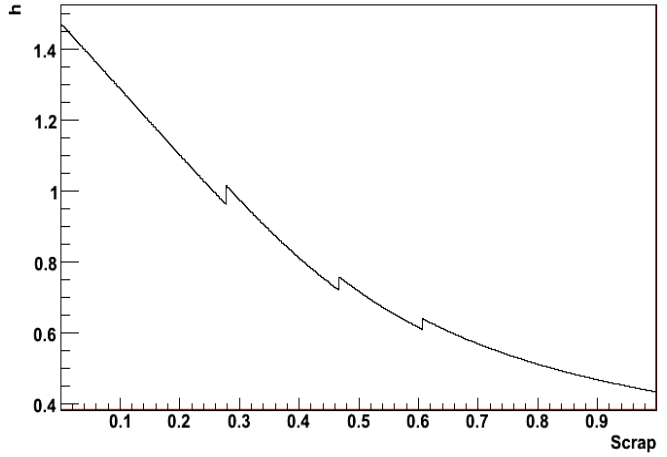

Figure 6: $h$, function of scrap rate

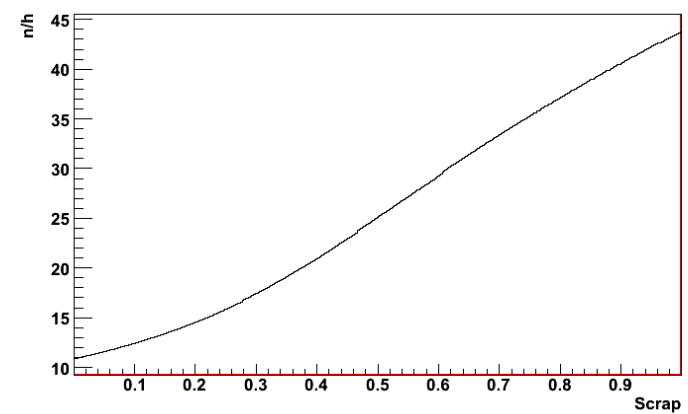

Figure 8: Evolution of the optimal quantity of control per hour depending on scrap rate

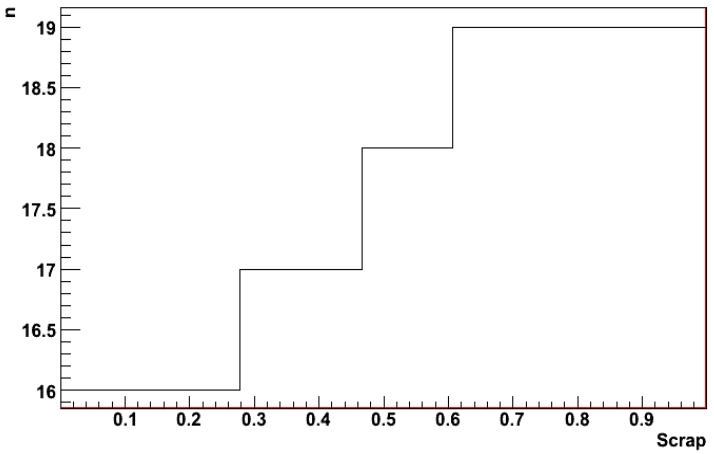

Figure 7: n, function of scrap rate

Figure 6 presents the frequency of control decreases dramatically, with slight peak augmentations when $\mathrm{n}$ increases.

Figure 7 presents number of units sampled is discrete. It increases slightly from 16 when scrap rate is below $28 \%$ to 19 above $62 \%$.

Figure 8 combines the two previous ones. Figure 8 shows the optimal solution for n, h, and the quantity of control (n / h) in function of the scrap rate.

When the scrap rate is null, optimum values are the classical economic design optimum. The quantity of control considerably increases with the scrap rate. The more scrap there are, the more controls have to be performed. Moreover, two major phenomena appear on the latter graph:

- The influence of the gain on investigation is strengthened with scrap rate, as more investigations happen, and the derivate of the quantity of control increase with scrap.

- Then, the expression of the gain on investigation weaken the influence of the quantity of control when $\mathrm{n} / \mathrm{h}>$ 30.

These two points are related to the gain function. Other gains would have provided other curves.

As pratical application, by anticipating scrap rate, it is possible to evaluate accurately the quantity of information needed for both process control and process learning. It rationalizes extensive sampling early in the product life cycle to achieve faster learning.

A simulation of yield learning phenomenon, is presented Figure 9. Yield increases following a $1^{\text {st }}$ order learning process from 5 up to $98 \%$ in 100 periods: minimum and maximum yield, yield evolution, and period length should be adjusted to the studied industry. 
In semiconductor industry, it is common to find such yield learning curves. Yield is just assimilated at (100-(Scrap rate)). Result presented Figure 9 can be used as a first tool for adjusting controls while yield increases, based on a economical approach.

\section{Conclusion}

In this paper, we presented an adaptation of the economic design of control charts by integrating that SPC measurements are valuable data for scraps analysis. Control charts are used for both monitoring locally the process and gathering information about each manufacturing steps. Scrap investigations duration are globally decreased by employing data analysis algorithms, which rely on SPC data.

The paper proposed a model enhancing the Lorenzen and Vance's Design economic model. The simulation leads at a new equilibrium of optimal sampling plan. Based on this model, the paper investigates also the impact of scrap rate evolution on optimal control plan. Several perspectives pursue this enhancement.

Final scrap rate and learning processes, locally and globally are considered as external variables of the model. In a next model, they could be considered as endogenous parameters.

Indeed, if $(\mathrm{n}, \mathrm{h})$ are modified, few data will be available for investigate scrap issues and related problems and then it could take more time to investigate. Lets' note $\mathrm{t}$ a discrete time period, It is understandable that change of $(\mathrm{n}, \mathrm{h})_{\mathrm{t}}$ leads at a change of $(\mathrm{S})_{t+1}$, which leads at a change of $(\mathrm{n}, \mathrm{h})_{\mathrm{t}+1}$ and so on. $(\mathrm{n}, \mathrm{h})_{\mathrm{t}}$ is then a function of previous $\mathrm{n}$ and $\mathrm{h}$ couples and scraps rate. $(\mathrm{n}, \mathrm{h})_{\mathrm{t}}=\Theta\left((\mathrm{n}, \mathrm{h})_{\mathrm{t}-1}, \ldots,(\mathrm{n}, \mathrm{h})_{0},(\mathrm{~S})_{\mathrm{t}},(\mathrm{S})_{\mathrm{t}-1}, \ldots,(\mathrm{S})_{0}\right)$. It is the same for $C_{0}$ and $C_{1}$ parameters. During this investigation, the stability of the model should be checked. The convergence toward an attraction pole should also be investigated.

A second investigation to lead is to take into account that process control has several layers of information [22], [23]: SPC, EPC, Run To Run, Alarms, Customer Feedbacks... Each of these layers generates data, which can be used for learning. It can be useful to take into account this new configuration to set control of each layer depending of its impact on yield learning.

A third extension of the paper could be $\mathrm{N}$ process stage instead of only one [24]. Stage correlations could be part of this extension. In this extension, the integration with WIP should also be taken into account.

Finally a full model: dynamic, multilayer and $\mathrm{N}$ process stage could be proposed. 


\section{References}

[1] F. Bergeret, Y. Chandon, and C. legall, "Use of statistics in industry, case study in Freescale (In French)," Journal de la Société Française de statistique, vol. 145, 2004, pp. 71-95.

[2] S. Gershwin and J. Kim , "Integrated Quality and Quantity Modeling of a Production Line," OR Spectrum, vol. 27, 2005, pp. 287-314.

[3] M. Colledani, "Integrated Analysis of Quality and Production Logistics Performance inManufacturing Lines,” IFAC World Congres Seoul, Vol 8368: 2008, pp. 1-7.

[4] T.J. Lorenzen and L.C. Vance, "The Economic Design of Control Charts: A Unified Approach," Technometrics, vol. 28, 1986, pp. 3-10.

[5] D. Montgomery, Introduction to Statistical Quality Control, John Wiley \& Sons, 2004.

[6] A.J. Duncan, "The Economic Design of X-bar Charts used to Maintain Current Control of a Process," Journal of the American Statistical Association, vol. 51, 1956, pp. 228-242.

[7] W. Jang, E.H. Wang, et R. Akella, "Economic in-line inspection sampling strategy with learning effects," International Journal of Production Research, vol. 38, 2000, pp. 4811-4821.

[8] W. Woodall, "Weaknesses of the economic design of control charts," Technometrics, vol. 28, 1986, pp. 408-409.

[9] E.M. Saniga, "Economic Statistical Control-Chart Designs with an Application to X and R Charts," Technometrics, vol. 31, 1989, pp. 313-320.

[10] K. Linderman and A.S. Choo, "Robust economic control chart design," IIE Transactions, vol. 34, 2002, pp. 1069-1078.

[11] V.B. Vommi and M.S. Seetala, "A new approach to robust economic design of control charts," Applied Soft Computing, vol. 7, 2007, pp. 211-228.

[12] S.S. Prabhu, D.C. Montgomery, and G.C. Runger, "Economic-statistical design of an adaptive X chart," International Journal of Production Economics, vol. 49, 1997, pp. 1-15.

[13] G. Tagaras, "A survey of recent developments in the design of adaptive control charts," Journal of quality technology, vol. 30, 1998, pp. 212-231.

[14] W.E. Deming and W. Edwards, Out of the crisis: quality, productivity and competitive position, Cambridge University Press, 1986. 
[15] E.A. Silver, "The economic design of an X control chart recognizing process improvement," International Journal of Production Research, vol. 37, 1999, p. 393.

[16] G.S. Weheba and D.M. Nickerson, "The Economic Design of X-bar Charts: A Proactive Approach," Quality and Reliability Engineering International, vol. 21, 2005, pp. 91-104.

[17] S. Bassetto and A. Siadat, "Operational methods for improving manufacturing control plans: case study in a semiconductor industry," Journal of Intelligent Manufacturing, vol. 20, Fév. 2009, pp. 55-65.

[18] J. Sterman, Business Dynamics, Systems thinking and modeling for a complex World, Erwin/McGraw-Hill, 2000.

[19] S. Bassetto, "Contribution to qualification and improvement of manufacturing system," PhD dissertation, ENSAM-Paritech,( in French), 2005.

[20] L. Argote and D. Epple, "Learning Curves in Manufacturing," Science, vol. 247, 1990, pp. 920-924.

[21] R.E. Bohn and C. Terwiesch, “The economics of yield-driven processes," Journal of Operations Management, vol. 18, 1999, pp.41-59.

[22] L. Yang and S. Sheu, "Economic design of the integrated multivariate EPC and multivariate SPC charts," Quality and Reliability Engineering International, vol. 23, 2007, pp. 203-218.

[23] K. Wonoh and t G. Vachtsevanos, "Hierarchical process control by combining SPC and soft computing methods," Fuzzy Information Processing Society, 2000. NAFIPS. 19th International Conference of the North American, 2000, pp. 485-489.

[24] Y.C. Lam, M. Shamsuzzaman, S. Zhang, and Z. Wu, "Integrated control chart systemoptimization of sample sizes, sampling intervals and control limits," International Journal of Production Research, vol. 43, 2005, pp. 563-582. 